\title{
Mapping Irrigated Area Fragments for Crop Water Use Assessment Using Handheld Spectroradiometer
}

\author{
S. Sovoe \\ Environmental Protection Agency, Field Operations, Volta Region, P.O. Box HP 513, Ho, Ghana \\ Correspondence should be addressed to S. Sovoe, sovo35@yahoo.com
}

Received 27 September 2010; Revised 8 March 2011; Accepted 10 August 2011

Academic Editor: Bernd Lennartz

Copyright () 2011 S. Sovoe. This is an open access article distributed under the Creative Commons Attribution License, which permits unrestricted use, distribution, and reproduction in any medium, provided the original work is properly cited.

As climatic change and land use are altering the hydrographic regime, most catchments are progressively becoming drier and farmers are shifting from rainfed agriculture to irrigation practices to enable them to carry out income-generating activities throughout the year. The Ghanaian government has recently been promoting irrigation agricultural practices as the population keeps increasing and the demand for food keeps soaring. In order to keep pace with high demand for food coupled with increasing aridity of the subregion, some farmers resort to informal irrigation practices. In this study, hyperspectral reflectance data of the irrigated crops under informal practices were collected to assess their efficiency of water use. Photochemical reflectance index (PRI), soil-specific nitrogen index (SSN), and water band index (WBI) were computed. The PRI and WBI were significantly correlated, while there was no significant correlation between PRI and SSN. The map showing the probability of water stress indicated that informal irrigation practices are not an efficient water management approaches.

\section{Introduction}

The will of individual nations to be self-sufficient has led to an increased development of irrigation facilities in recent times with potential further increases in the coming years [1]. The increase in the use of irrigation has put a serious stress on freshwater resources [2,3]. Further development of irrigable lands and efficient management of existing ones requires knowledge of the spatial extent, of crop types, cropevapotranspiration patterns, basin hydrology, and the impact of different types of irrigation on watersheds including inland valleys [4]. This knowledge will assist in development of a spatial decision support system to assist policy makers [5]. The Ghanaian government has recently been promoting irrigation as part of agricultural practice. However, irrigation facilities and their development are costly; hence, not all farmers are covered under state-initiated irrigation development projects. Sometimes due to poor maintenance these facilities, frequently break down rendering the farmers inactive. As a result of this lack of conventional irrigation facilities, some farmers resort to improvised ways of watering their crops. One such method is currently under way in the Atankuidi River basin in the Upper East Region of Ghana, where the inland valley is used by the communities along the river for cultivation of vegetables during the dry season.

Atankuidi is a seasonal river, drying up during the dry season. During the rainy season the communities cultivate cereals such as millet, sorghum, maize, and rice. During the dry season the only available water is underground water. Farmers, who own land along the river and within the inland valley, cultivate vegetables especially tomatoes using ground water for irrigation. Farmers access ground water from wells dug on their farms that can be as deep as $20 \mathrm{~m}$. A farmer can have several such wells depending on the size of his farm. Those who are very close to the river bank dig the well in the river bed, and the water is pumped by machine to irrigate their crops. This irrigation method is quite wasteful since sprinklers or drip systems are not used. It is therefore not used for wells which are not in the river bed due to the small amount of water they contain. Informal irrigation is very labour intensive since the farmer must move from crop to crop which therefore limits the acreage that can be cultivated. Farmers also assert that those who are close to the river bank and own pumping machines have better yields than those that have wells further from the river. Thus, not all farmers who use irrigation gain the higher yields they expect. 
As fresh water resources keep dwindling, prudent water management is required. The Food and Agriculture Organization (FAO) advocates optimum use of water for food production [6, 7]. Developing countries use most of their fresh water resources for food production. It is estimated that India uses approximately $90 \%$ of her water resources in agriculture with only $7 \%$ for industrial purposes and 3\% for domestic use [8]. The global estimates for the sectors are 69\% for agriculture, $23 \%$ for industries, and $8 \%$ for domestic use [8].

Crop water requirement is the amount of water a healthy crop requires to balance the amount that is lost through evapotranspiration (ET) so as to achieve maximum yield [9]. If irrigation exceeds evapotranspiration (ET), waterlogging or salinization can occur and excess percolation results in leaching of nitrates and pesticides into ground water [10]. Conversely, if irrigation rate is less than ET, the crop is stressed which results in poor yield [9]. Measuring ET for each crop type could be a difficult task as this will require determination of potential evapotranspiration (PET) for each type. Potential evapotranspiration is defined by Thornthwaite [11] as the rate at which evapotranspiration will occur from a large area uniformly covered with growing vegetation that has an access to unlimited supply of soil water and that was not exposed to advection or heat storage effect. Several methods have been developed to estimate PET which usually requires estimation of various input parameters. For instance, the Penman-Monteith method requires measures of solar radiation, air temperature, relative humidity, and wind speed. The Priestley-Taylor method uses solar radiation, air temperature, and relative humidity, whereas the Hargreaves method uses only air temperature [12]. Alternatively, a class "A" evaporation pan can be used which combines all parameters mentioned above alongside the crop coefficient. However, this method will require training of local farmers on how it works in relation to specific crop water requirement. Although recent developments in remote sensing can help estimate PET, obtaining irrigation measures on a daily basis requires real-time data and is costly. Moreover, spatial resolution will be a difficult issue for small farms. It is therefore important to seek indirect methods of determining crop water needs that can be shared with farmers.

This research investigated the usefulness of hyperspectral data to assess efficiency of water use by crops under informal irrigation practices. It was conducted in four communities in the Atankuidi basin (a tributary of White Volta River) in the Upper East Region of Ghana

\section{Methods}

2.1. The Study Area. The study was carried out in the Atankuidi River basin in the Ghanaian segment of the Volta Basin. This segment of the basin stretches from the midsection of the country $\left(7^{\circ} 30^{\prime} 20.35^{\prime \prime} \mathrm{N}, 2^{\circ} 59^{\prime} 47.22^{\prime \prime} \mathrm{W}\right.$ to $\left.7^{\circ} 10^{\prime} 24.80^{\prime \prime} \mathrm{N}, 1^{\circ} 09^{\prime} 10.09^{\prime \prime} \mathrm{E}\right)$ to the northern section bordering Togo in the east, Burkina Faso in the north, and Cote d'Ivoire in the west. The southeastern section ends at $5^{\circ} 46^{\prime} 11.60^{\prime \prime} \mathrm{N}, 0^{\circ} 43^{\prime} 02.74 \mathrm{E}^{\prime \prime}$, where the Volta River empties into the Atlantic Ocean. The area covers a total of 167, 692 square kilometres (70\% of the country's total land area) constituting $40.18 \%$ of the total area of the Volta River Basin (417,382 square kilometres) [13-16]).

The Volta Lake Reservoir has a surface area of approximately 8,500 square kilometres with approximately $4,800 \mathrm{~km}$ shoreline of an average depth of 18.8 metres with the deepest portions around depths of 90 metres $[13,16]$. The total reservoir volume estimate at full supply of 84.73 metres is 150 billion cubic metres $\left(148 \mathrm{~km}^{3}\right.$ and a live storage volume of $60 \mathrm{~km}^{3}$ ) with seasonal rise and fall range of 2.0-6.0 metres $[13,14]$. Total evaporation from the Volta Lake is $10.2 \mathrm{~km}^{3}$ which is compensated by $7.3 \mathrm{~km}^{3}$ of rainfall with a net loss of $7.5 \%$ of total flow [17]. The area is drained by several major rivers: the Black Volta, the White Volta with the Red Volta as its tributary, the Oti River, and the Lower Volta [16, 18, 19]. The mean annual flows of the Black Volta, White Volta, and Oti River are $8,300 \times 10^{6}, 8,180 \times 10^{6}$, and $12,606 \times 10^{6}$, respectively [16]. The Oti River with only about $18 \%$ of the total catchment area contributes between $30 \%$ and $40 \%$ $\left(500 \mathrm{~m}^{3} / \mathrm{sec}\right)$ of the annual flow of the Volta River System; this is due to the steep topography and the relatively high rainfall in the Oti subbasin $[16,19,20]$.

The population in the area is estimated to increase from the current figure of 7 million to approximately 12 million with an annual growth rate of $2.5 \%$. Eighty-four percent (84\%) of the population are rural dwellers [21]. The basin supports Ghana's main staple foods such as yam, maize, cassava, sorghum, and millet.

2.2. Climate of the Study Area. The climate of the study area is controlled by two air masses, namely, the Northeast Trade Winds and the Southwest Trade Winds. The Northeast Trade Winds (the Harmattan) blow from the interior of the continent and are dry, while the Southwest Trade Winds (the Monsoons) blow from the seas and are wet [18]. The interphase of the two air masses (the Intertropical Convergence Zone-ITZC) moves northwards and southwards across the study area from March to October [18]. Precipitation in the study area is believed to be greatly influenced by convective activity in the region of the ITCZ with three types of climatic zones, the humid south with two distinct rainy seasons; the tropical transition zone with two seasons of rainfall very close to each other, and the tropical climate, north of latitude $9^{\circ} \mathrm{N}$, with one rainfall season that peaks in August [18]. Thus, the rainy season starts from March to October and the dry season starts from November to February. Sometimes, the dry season stretches beyond this period rendering rainfed agriculture practically impossible.

2.3. Reflectance Data Collection. Reflectance data of tomato crops in the Atankuidi basin were collected using ASD FieldSpec HandHeld $(\mathrm{HH})$ model, UV/VNIR Spectroradiometer instrument of 16-bit radiometric resolution [22]. The Visible/Near-Infrared (VNIR) spectrum, 325-1075 nanometre wavelength domain, was measured with a 512-channel silicon photodiode array overlaid with an order separation filter with a narrow $(1.6 \mathrm{~nm})$ nominal bandwidth [22]. At each sampling point 5 to 15 measurements were taken at $1 \mathrm{~m}$ 
vertically above the crops. Measurements were taken between 11:00 AM and 1:00 PM GMT when the sun is at near zenith position. Data were collected during clear and nonwindy weather conditions. The measurements were averaged to a single spectrum value for each location. Each sampling point was georeferenced using a Trimble differential GPS device. The data were imported into GIS software. The geographic coordinates were transformed into metric coordinate system using Universal Transverse Mercator Projection System.

2.4. Vegetation Index Calculation. Several indices were calculated from the reflectance data to assess the health of the crops under informal irrigation practices. The indices computed from the reflectance data included modified red edge normalized difference vegetation index $\left(\mathrm{mNDVI}_{705}\right)$, water band index (WBI), photochemical reflectance index (PRI), and soil specific nitrogen index (SSN). Indices were interpolated over the sampled area to depict their spatial variation.

2.5. Calculation of $m N D V I_{705}$. Modified red edge normalized difference index $\left(\mathrm{mNDVI}_{705}\right)$ is one of the narrowband greenness vegetation indices and is a sophisticated measure of general quantity and vegetation vigour [23, 24]. Its value ranges from -1 to $1[23,24]$. Measuring in the red edge portion of the vegetation reflectance spectrum makes it more sensitive to slight changes in vegetation health compared to the traditional broadband indices $[23,24]$. It is applied in precision agriculture to identify, analyse, and manage sitesoil spatial and temporal variability $[23,24]$.

Modified red edge normalised difference vegetation index $\left(\mathrm{mNDVI}_{705}\right)$ was computed by the following equation $[23,24]$ :

$$
\mathrm{mNDVI}_{705}=\frac{(\mathrm{R} 750-\mathrm{R} 705)}{(\mathrm{R} 750+\mathrm{R} 750)-(2 * \mathrm{R} 445)} .
$$

2.6. Computation of Water Band Index. Water band index (WBI) for each point was calculated by rationing reflectance at $970 \mathrm{~nm}$ and $900 \mathrm{~nm}$ [25]. Water band index (WBI) which ranges from 0.8 to 1.2 [25] measures plant leaf water content. Leaf water affects plant reflectance in the near-infrared and short waves infrared regions of the spectrum [25]. As the water content of the vegetation canopies increases, the strength of the water absorption feature centered at $970 \mathrm{~nm}$ increases relative to absorption feature at $900 \mathrm{~nm} \mathrm{[25].} \mathrm{A}$ ratio of reflectance at $970 \mathrm{~nm}$ (R970) and $900 \mathrm{~nm}$ (R900) gives an index for productivity prediction and modeling [25]:

$$
\mathrm{WBI}=\frac{\mathrm{R} 970}{\mathrm{R} 900} \text {. }
$$

2.7. Calculation of Photochemical Reflectance Index. Photochemical reflectance index (PRI) is an index that is sensitive to variations in carotenoid pigment concentration in green plants such as xanthophyll which is an indicator of photosynthetic light use efficiency or a measure of carbon dioxide uptake per unit energy absorption [26, 27]. PRI ranges from -1 to 1 [26] and is used in assessing crop productivity and is also a measure of the onset of environmental stress.
Photochemical reflectance index (PRI) was calculated as a ratio of the difference of the reflectance at $531 \mathrm{~nm}$ and $570 \mathrm{~nm}$ and their sum as follows [26, 27]:

$$
\mathrm{PRI}=\frac{\mathrm{R} 531-\mathrm{R} 570}{\mathrm{R} 531+\mathrm{R} 570}
$$

2.8. Calculation of Soil-Specific Nitrogen Index. Soil-specific nitrogen index (SSN) is soil nitrogen status index which uses information on reflectance at the inflection point (Rre) and red edge wavelength (Lre). The reflectance at the inflexion point (Rre) was calculated by interpolating it from nearby reflectance points as follows [28]:

$$
\text { Rre }=\frac{(\mathrm{R} 670-\mathrm{R} 780)}{2} .
$$

The red edge wavelength (Lre) was computed using the equation below [27]:

$$
\text { Lre }=700+40 *\left[\frac{(\text { Rre }-\mathrm{R} 700)}{(\mathrm{R} 740-\mathrm{R} 700)}\right]
$$

Soil Specific Nitrogen Index (SSN) is related to the red edge wavelength (Lre) by the following equation [28]:

$$
\text { Lre }=5 * a \log (\mathrm{SSN})+721 .
$$

Nutrient availability for each sampled point was estimated from soil-specific nitrogen index (SSN) using the following equation [28]:

$$
\mathrm{SSN}=\operatorname{EXP}\left(\frac{(\text { Lre }-721)}{5}\right)
$$

2.9. Bivariate and Multivariate Data Analysis. Regression analysis was carried out to establish the degree of correlation between the indices. Photochemical reflectance index (PRI) which is a measure of productivity was plotted against water band index (WBI). This was carried out to establish the correlation between the foliage water status of the crops and productivity index. The equations relating PRI and WBI indices for the four communities were derived, and percentage of variation of PRI that is explained by the equations was generated. Similar analysis was carried out between the PRI and soil-specific nitrogen index (SSN). Multiple regression analysis was also carried out with PRI as the dependent variable, WBI and SSN as independent variables.

2.10. Water Stress Mapping. A threshold value of 0.95 based on the performance of the crops was set as minimum water band index (WBI). Using $\mathrm{R}$ programming environment loaded with geo-statistical software (gstat) and lattice packages, the WBI index at all the sampled points was converted into indicator variables where all the points with WBI < 0.95 were assigned 1 (true) and those that exceeded the threshold were assigned 0 (false). Spatial distribution of the indicator variables for the four sites was plotted with red colour assigned to true and green to false. The empirical indicator variograms for the sites were computed, and their 


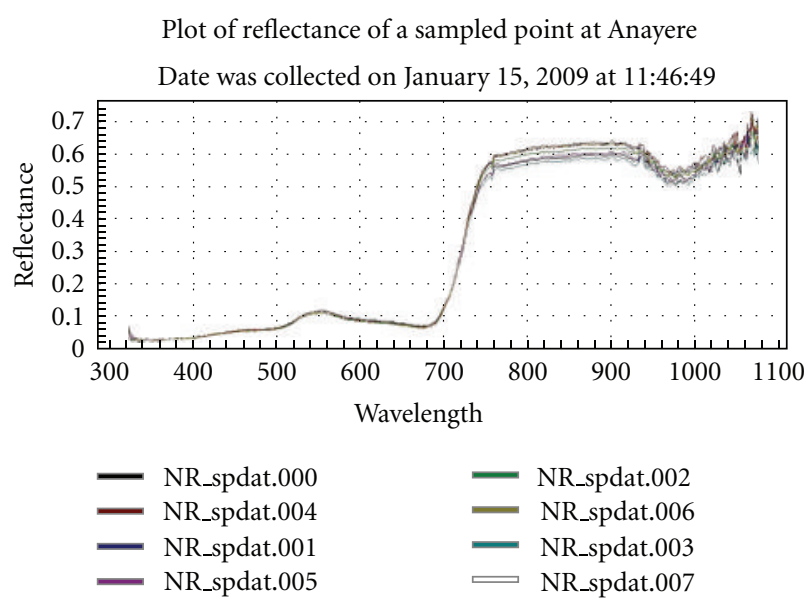

Figure 1: A plot of spectral reflectance curve of tomato crop at Anayere.

corresponding nugget, sill, and range were estimated. The best models were constructed and fitted. Based on the modeled variograms, the probability of true variables (1), were predicted over a prediction grid created by spatial grid method of spatial package (sp).

\section{Results}

3.1. Reflectance Spectrum $(320-1100 \mathrm{~nm})$. A plot of reflectance curves of one of the sampled points at Anayere exhibited typical green vegetation optical properties (Figure 1). There was nonspecific fashion absorption by biological components in the ultraviolet region of the spectrum (320$400 \mathrm{~nm}$ ). High chlorophyll absorption peak centres 420, 490 , and $660 \mathrm{~nm}$ were obvious in the reflectance curve (Figure 1). The red-edge shoulder which is a transition from chlorophyll absorption and near-infrared leaf scattering was very distinctive and broad $(690-750 \mathrm{~nm})$. There was high reflectance in the near-infrared region $(700-1100 \mathrm{~nm})$ with some water absorption peak around $970 \mathrm{~nm}$ (Figure 1).

3.2. Spatial Variation of the Indices. The results show a spatial correlation of the vegetation indices. Lower values of the modified red edge normalized difference vegetation index occurred in the northern and middle portions of the Anayere samples. There is a stronger spatial variation between the computed water band index (WBI) and photochemical reflectance index (PRI) (Figures 2 and 3). Areas with lower values of modified red edge normalized difference vegetation index $\left(\mathrm{mNDVI}_{705}\right)$ had higher water band indices. Better spatial variation in the crops is resolvable by photochemical reflectance index (PRI) (Figure 3). Areas with high water band index (WBI) show higher carbon dioxide $\left(\mathrm{CO}_{2}\right)$ absorption or higher photosynthetic activity (Figures 2 and 3). Areas with green colour correspond with higher carbon dioxide absorption $\left(\mathrm{CO}_{2}\right)$ rate, whereas areas with red colour correspond with low carbon dioxide $\left(\mathrm{CO}_{2}\right)$ absorption rate (Figure 3). Spatial pattern of variation in the computed soil-specific nitrogen index correspond to the

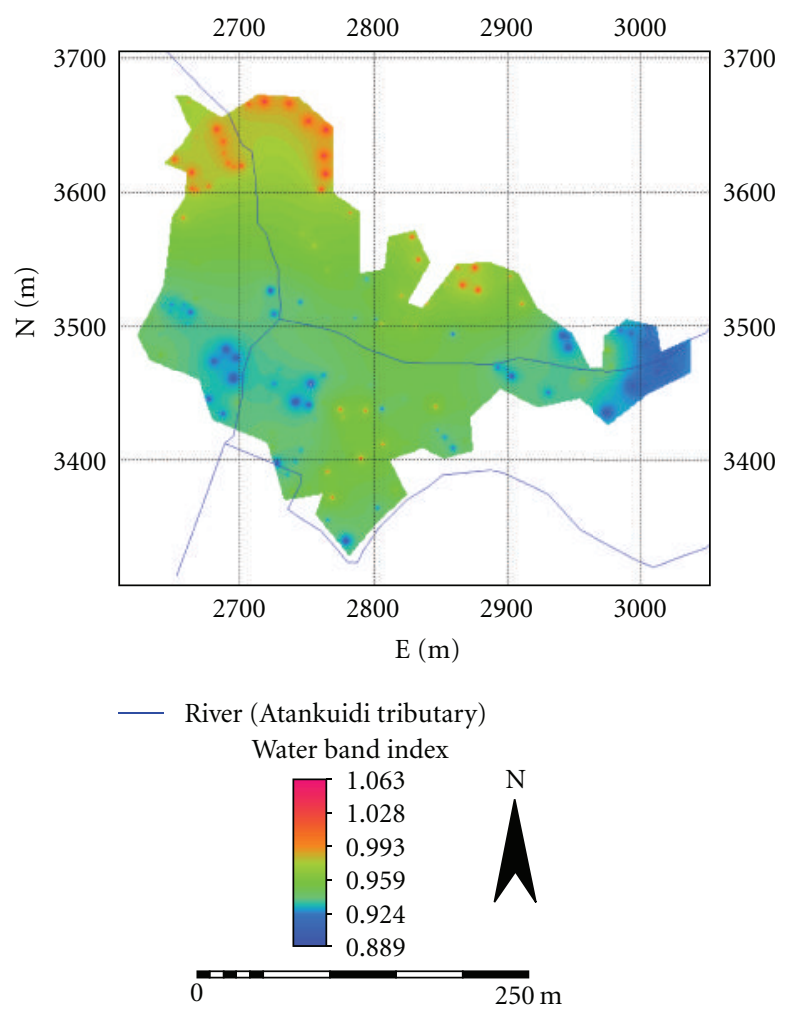

FIGURE 2: Spatial variation of computed water band index.

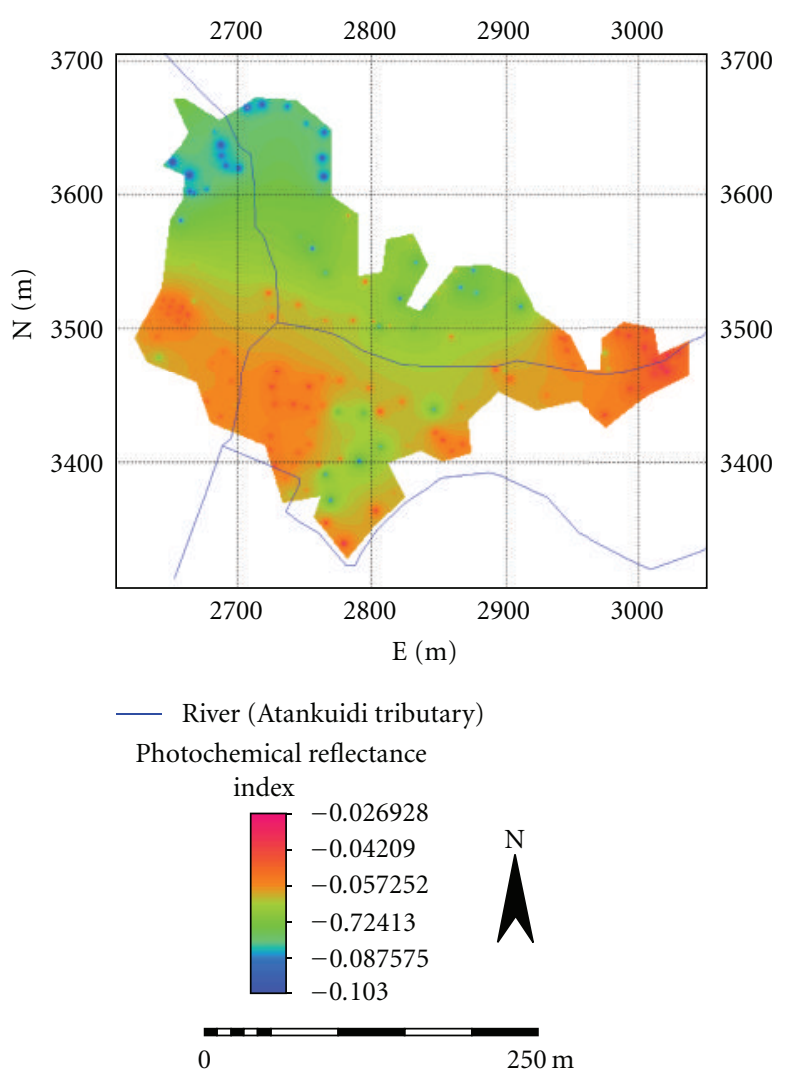

FIgURE 3: Spatial variation of photochemical reflectance indices. 


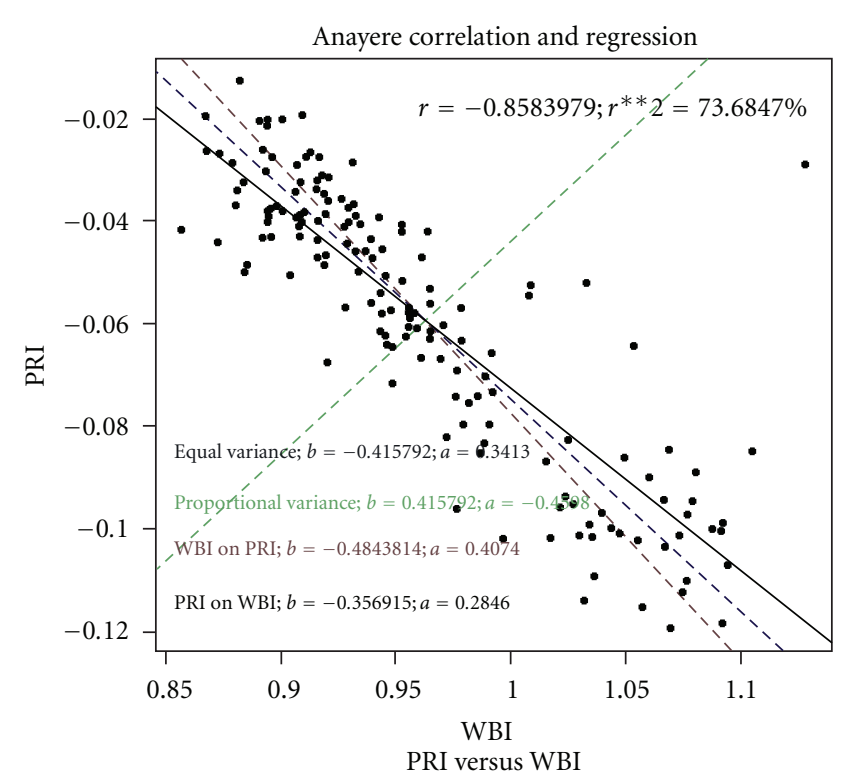

(a)

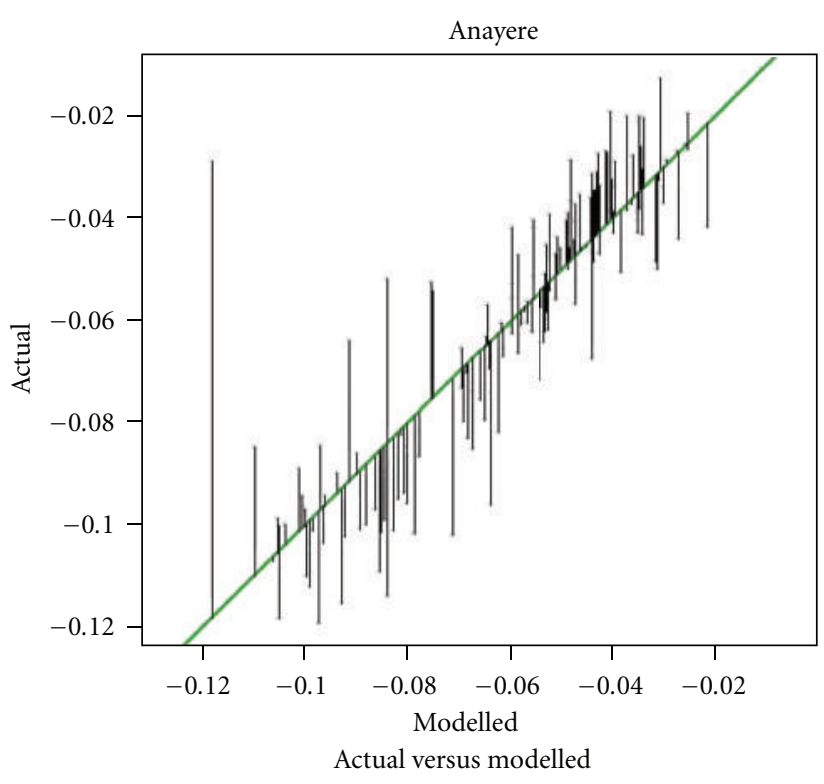

(b)

FIGURE 4: Ordinary least-square regression, PRI versus WBI at Anayere, with actual versus modeled.

other indices however, subtle variations could not be resolved as exhibited by photochemical reflectance index.

3.3. Bivariate Data Analysis. There was a strong negative correlation between photochemical reflectance index (PRI) and water band index (WBI). At Anayere $73.68 \%$ of PRI variation is explained by WBI (Figure 4), at Alia $69.74 \%$ of variation in PRI is explained by WBI, at Atankuidi $60.77 \%$ of the variation is explained by WBI, and at Bimbisi $49.04 \%$ of the variation in PRI is explained by WBI. There was a poor correlation between PRI and SSN suggesting that soil nitrogen status was not a determining factor of crop performance in all the areas sampled.

A diagnostic analysis of the regression shows good performance of the models. Plots of the residuals' distances to the best fit lines show good fit except at Anayere where one of the vertical lines is far away from the best fit line (Figure 4(b)). Plots of the residuals against the fitted models with horizontal lines of $\pm 3, \pm 2$, and \pm 1 standard deviations of the residuals superimposed showed good fit of the models with only one point lying outside \pm 3 standard deviation. Most of the points fall within \pm 2 and \pm 1 standard deviations (Figure 5(a)). Normal quantile-quantile plots of the residuals of all the four sample areas showed very good performance of the models (Figure 5(b)).

3.4. Probability Kriging of Water Stress Areas. At Anayere, $52.20 \%$ of the observations fell below the threshold value of 0.95 of WBI (Figure 6(b)). At Alia, 64.47\% of the observations fell below the threshold value of 0.95 of WBI. At Atankuidi, 62.05\% of the observations were below the threshold, and, at Bimbisi, 93.20\% of the observations were below the threshold. Postplot of the WBI at Anayere exhibits areas with lower WBI values (Figure 6(a)). The spatial distributions of the points correspond to spatial variations observed in the other indices such as photochemical reflectance index (PRI) and modified red edge normalized difference vegetation index $\left(\mathrm{mNDVI}_{705}\right)$. The probability maps of the sample areas showed clearly that large areas have high probability of having WBI values below the threshold value (Figure 7(b)).

\section{Discussion}

Productivity, represented here by photochemical reflectance index (PRI), is correlated with water band index. PRI is a measure of absorption rates of atmospheric carbon dioxide $\left(\mathrm{CO}_{2}\right)$ by crops; thus, there will be a greater rate of carbon dioxide absorption where there is higher photosynthetic activity and higher yields. Although nutrient availability is one of the main determinants of crop yield [28], in this study the soil specific nitrogen index (SSN) was not correlated with PRI. This result could be due to the fact that synthetic fertilizer was applied to boost the soil nutrient concentration. PRI also increased as WBI increased; that is, the higher the value of WBI, the more the photosynthetic activity. Thus, water availability is more important than nutrient availability for crops in the study site suggesting that informal irrigation practices within Atankuidi catchment of the Volta basin are not efficient.

This study showed that both the position and slope of the red edge of the electromagnetic spectrum changed under stress conditions resulting into a blue shift of the red edge position. Stress may cause biochemical changes at the cellular and leaf level, which may have influence on pigment systems and the canopy moisture content [28]. Reflectance spectra of natural surfaces are sensitive to specific chemical bonds in materials, whether solid, liquid, or gas [29]. Variation in the composition of materials causes shifts in the 


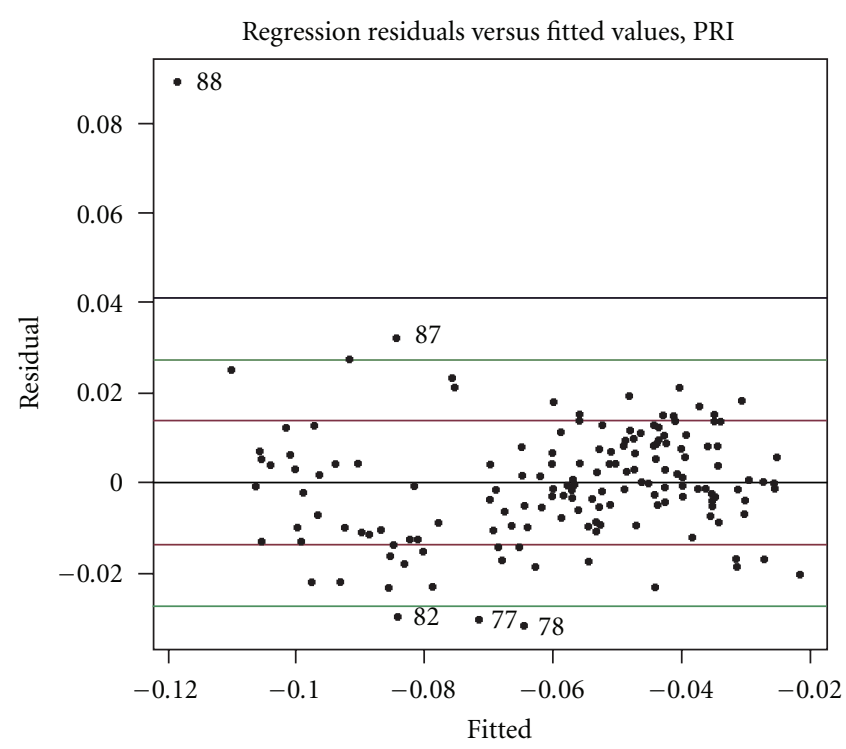

(a)

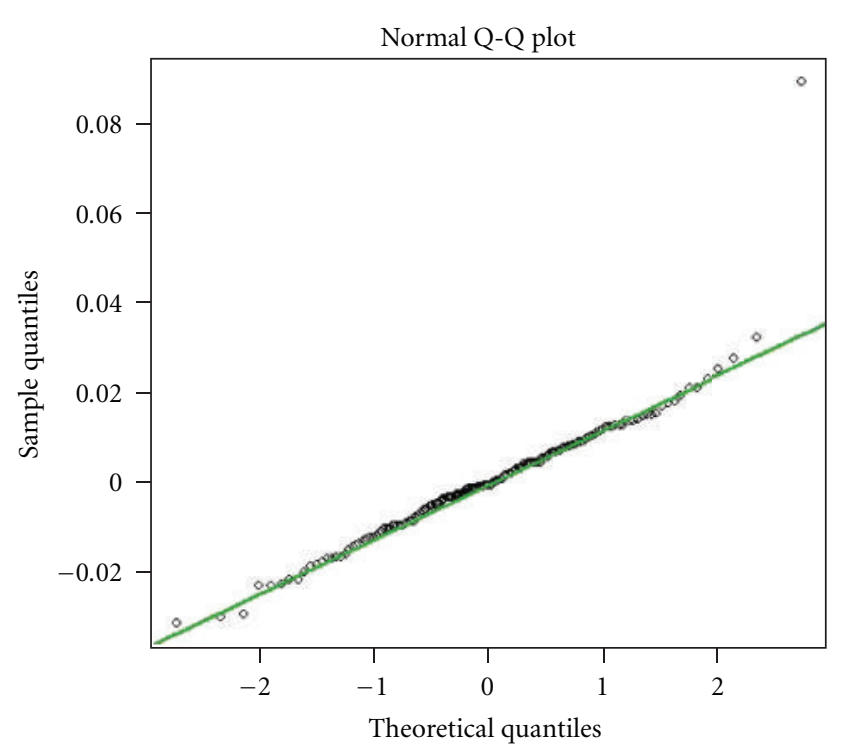

(b)

FIGURE 5: Diagnostics check of the regression performance of PRI versus WBI at Anayere.

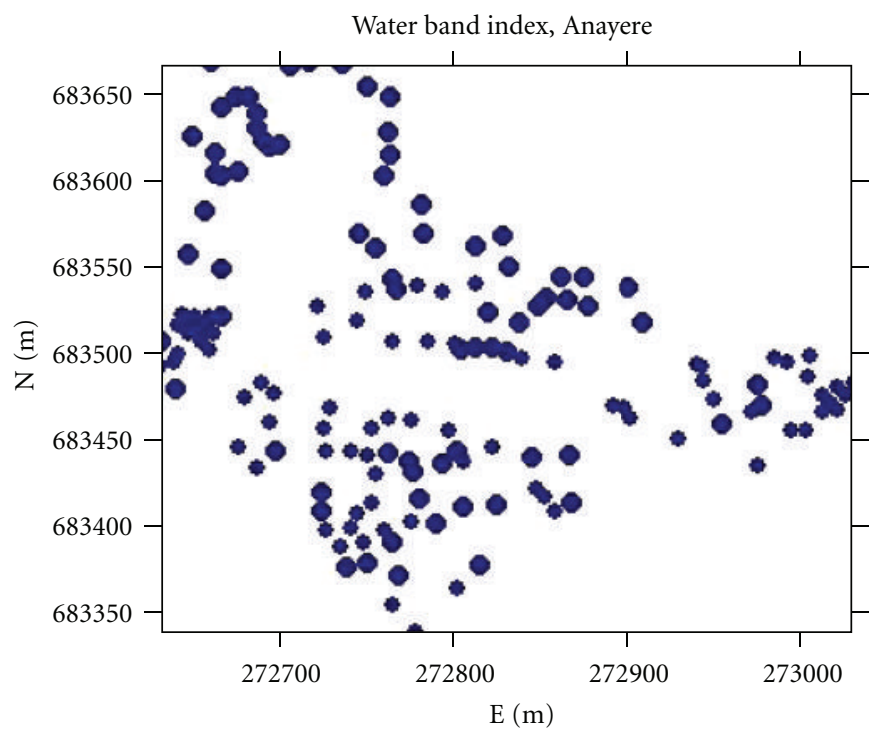

WBI; symbol size proportional to value

\begin{tabular}{|c|c|}
\hline 0.857 & 0.965 \\
\hline 0.894 & 0.987 \\
\hline 0.909 & 1.031 \\
\hline 0.92 & 1.07 \\
\hline 0.932 & 1.129 \\
\hline
\end{tabular}

(a)

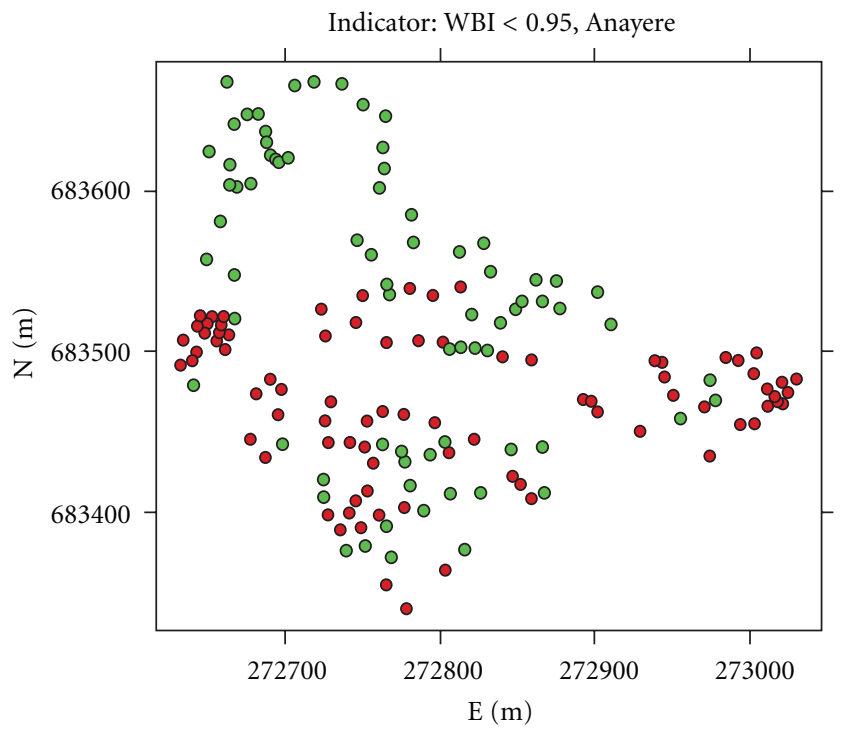

- False

- True

Figure 6: Post-plots of water band index and its corresponding indicator variables at Anayere.

position and shape of absorption bands in the spectrum [29]. Water availability is a critical factor in plant survival and development and water stress is one of the most common limitations of primary productivity [30]. Thus, the ability to assess water stress symptoms in vegetation using spectral reflectance measurements is an important goal for remote sensing research [31]. In agricultural crops it is important to be able to detect the onset of water stress as early as possible so that preventive measures such as irrigation can be undertaken [29]. 


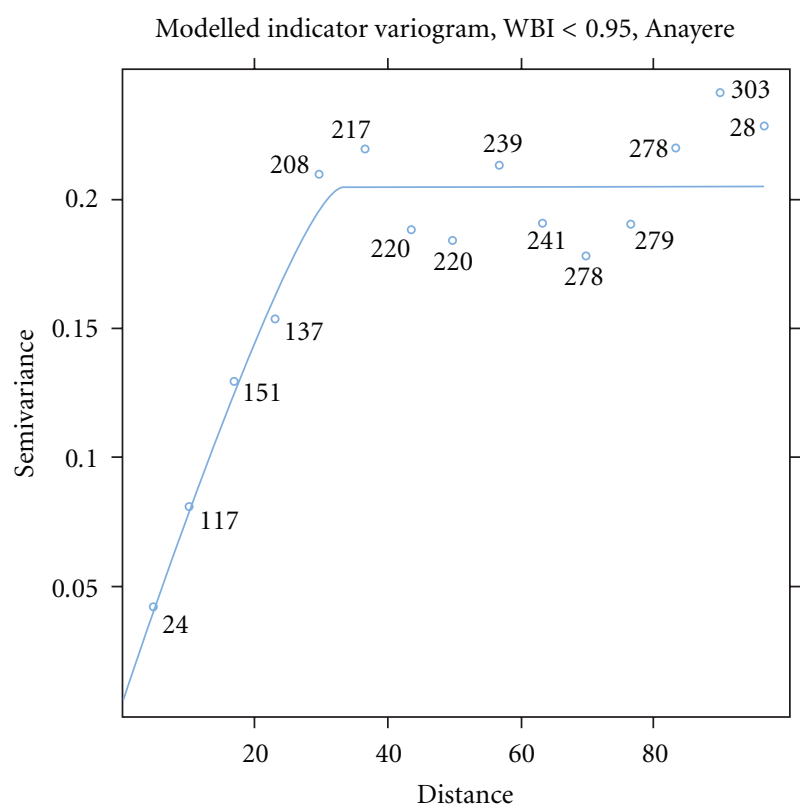

(a)

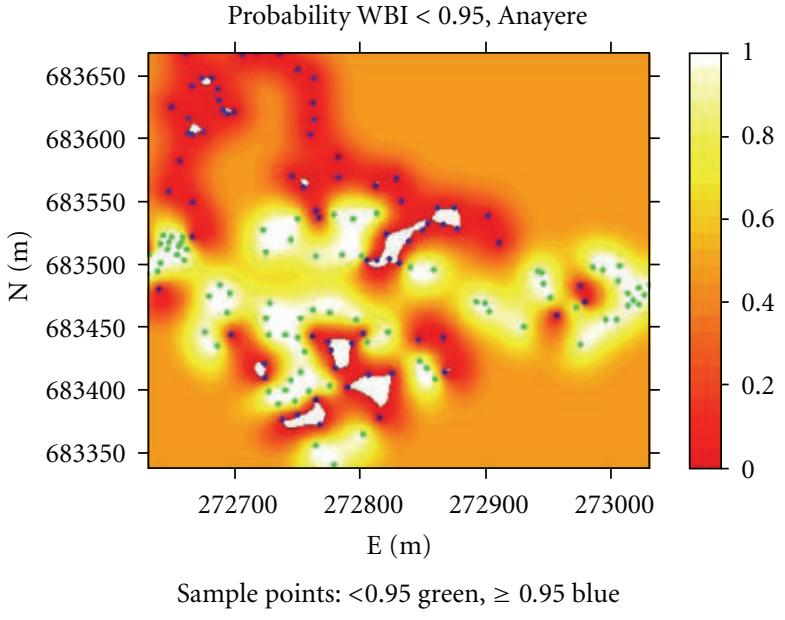

(b)

Figure 7: Probability of crop water stress risk map at Anayere.

\section{Conclusions}

Hyperspectral remote sensing data can play a significant role in irrigation management. Its ability to sample in narrow bands and contiguously across the electromagnetic spectrum makes it possible for important biophysical absorption features to be exploited in environmental management. This study showed that informal irrigation practice like the one ongoing in the Atankuidi catchment area is not efficient. It is therefore not a sustainable water resources management approach. By applying geostatistical risk mapping approach, areas with potential water deficiency could be delineated to aid in irrigation scheduling. Fertilizer application scheduling could also be enhanced by applying geostatistics risk mapping to highlight areas with potential nitrogen deficiency. Hyperspectral remote sensing is a precision agricultural tool that can be used to improve crop productivity. It could also be used to reduce the amount of nutrient loadings into both surface and underground water bodies since fertilizer would be applied only in areas with less soil nutrients which can be computed from foliage reflectance data.

\section{Acknowledgments}

The author is completely indebted to International Foundation for Science (IFS), Swedish International Development Cooperation Agency (SIDA), NATUR, and OIC's Standing Committee on Scientific and Technological Cooperation for the Promotion and Cooperation of Science and Technology (COMSTECH) for the funding support for this project (Grant no. W/4300-1). He extends his sincere gratitude to Mr. Eli Sokpoli of GLOWA, Ghana for his immense help during his field work. He is grateful to individuals who for one way or the other contributed to the success of this work. For the information of readers, he has no financial sponsorship from the manufacturers of the equipment used neither was he commissioned by the company to undertake this research. This research was undertaken by the author purely for academic purposes and may not be used for any commercial intent.

\section{References}

[1] P. S. Thenkabail, M. Schull, and H. Turral, "Ganges and Indus river basin land use/land cover (LULC) and irrigated area mapping using continuous streams of MODIS data," Remote Sensing of Environment, vol. 95, no. 3, pp. 317-341, 2005.

[2] P. S. Thenkabail, N. Gamage, and V. Smakhin, "The use of remote sensing data for drought assessment and monitoring in south west Asia," IWMI research report number 85, IWMI, Colombo, Sri Lanka, 2004.

[3] I. A. Shiklomanov, "Appraisal and assessment of world water resources," Water International, vol. 25, no. 1, pp. 11-32, 2000.

[4] D. M. Rosenberg, P. McCully, and C. M. Pringle, "Globalscale environmental effects of hydrological alterations: introduction," BioScience, vol. 50, no. 9, pp. 746-751, 2000.

[5] T. W. Biggs, P. S. Thenkabail, M. K. Gumma, C. A. Scott, G. R. Parthasaradhi, and H. N. Turral, "Irrigated area mapping in heterogeneous landscapes with MODIS time series, ground truth and census data, Krishna Basin, India," International Journal of Remote Sensing, vol. 27, no. 19, pp. 4245-4266, 2006.

[6] N. Lamaddalena and J. A. Sagardoy, "Performance analysis of on-demand pressurized irrigation systems," FAO irrigation and drainage, paper 59, 2000.

[7] D. Renault, T. Facon, and R. Wahaj, "Modernizing irrigation management - the MASSCOTE approach. Mapping system and services for cal operation techniques," FAO irrigation and drainage, paper 63, 2007.

[8] D. M. Tate and Scarf, Water use in Canadian Industry, Environment Canada, 1991. 
[9] "Chapter 1-introduction to evapotranspiration," http://www .fao.org/docrep/x0490e/x0490e04.htm.

[10] L. C. P. M. Stuyt, W. Dierickx, and J. M. Beltran, "Materials for subsurface land drainange systems," FAO irrigation and drainage, paper 60, 2005.

[11] C. W. Thornthwaite, "An approach toward a rational classification of climate," Geographical Review, vol. 38, pp. 55-94, 1948.

[12] P. E. Dodds, W. S. Meyer, and A. Barton, "A review of methods to estimate irrigated reference crop evapotranspiration across Australia," Tech. Rep. number 04/05, CRC for Irrigation Futures, 2005.

[13] B. Barry, E. Obuobie, M. Andreini, W. Andah, and M. Pluquet, "Comprehensive assessment of water management in agriculture (comparative study of river basin development and management," 2005.

[14] C. Leemhuis, G. Jung, R. Kasei, and J. Liebe, "The Volta Basin water allocation system: assessing the impact of small-scale reservoir development on the water resources of the Volta basin, West Africa," Advances in Geosciences, vol. 21, pp. 5762, 2009.

[15] S. Opoku-Duah, D. N. M. Donoghue, and T. P. Burt, "Intercomparison of evapotranspiration over the Savannah Volta Basin in West Africa using remote sensing data," Sensors, vol. 8, no. 4, pp. 2736-2761, 2008.

[16] C. Gordon and J. A. Amatekpor, Eds., The Sustainable Integrated Development of the Volta Basin in Ghana. Volta Basin Research Project, Accra, Accra, Ghana, 1999.

[17] M. Andreine, N. van de Giesen, A. van Edig, M. Fosu, and W. Andah, "Volta Basin water balance," ZEF Discussion Paper number 21, ZEF, Bonn, Germany, 2000.

[18] B. Barry, E. Obuobie, M. Andreini, W. Andah, and M. Pluquet, The Volta River Basin, 2005, http://www.iwmi.cgiar. org/assessment/files_new/research_projects/River_Basin_Development_and_Management/VoltaRiverBasin_Boubacar.pdf.

[19] N. van de Giesen, J. Liebe, and G. Jung, "Adapting to climate change in the Volta Basin, West Africa," Current Science, vol. 98, no. 8, pp. 1033-1037, 2010.

[20] African Water Resources Database, Concepts and Applications Case Studies, vol. 109.

[21] W. Andah, N. van de Giesen, A. Huber-Lee, and C. B. Biney, "Can we maintain food production without losing hydropower? The Volta basin (West Africa)," in Climate Change in Contrasting River Basins, J. C. J. H. Aerts and P. Droogers, Eds., pp. 181-194, CABI, Wallingford, UK, 2004.

[22] Analytical Spectral Devices, "Handheld spectroradiometer user's guide," ASD part no. 600300, Rev. C, 2003.

[23] B. Datt, "A new reflectance index for remote sensing of chlorophyll content in higher plants: tests using eucalyptus leaves," Journal of Plant Physiology, vol. 154, no. 1, pp. 30-36, 1999.

[24] D. A. Sims and J. A. Gamon, "Relationships between leaf pigment content and spectral reflectance across a wide range of species, leaf structures and developmental stages," Remote Sensing of Environment, vol. 81, no. 2-3, pp. 337-354, 2002.

[25] J. Penuelas, I. Filella, C. Biel, L. Serrano, and R. Save, "The reflectance at the $950-970 \mathrm{~nm}$ region as an indicator of plant water status," International Journal of Remote Sensing, vol. 14, no. 10, pp. 1887-1905, 1993.

[26] J. A. Gamon, J. Penuelas, and C. B. Field, "A narrow-waveband spectral index that tracks diurnal changes in photosynthetic efficiency," Remote Sensing of Environment, vol. 41, no. 1, pp. 35-44, 1992.
[27] J. A. Gamon, L. Serrano, and J. S. Surfus, "The photochemical reflectance index: an optical indicator of photosynthetic radiation use efficiency across species, functional types, and nutrient levels," Oecologia, vol. 112, no. 4, pp. 492-501, 1997.

[28] F. D. Van der Meer and S. M. de Jong, Imaging Spectrometry. Remote Sensing and Digital Image Processing, Springer, Berlin, Germany, 2006.

[29] L. Kumar, K. Schmidt, S. Dury, and A. Skidmore, "Imaging spectrometry and vegetation science," in Imaging Spectrometry, F. D. van der Meer and S. M. de Jong, Eds., pp. 111-155, 2006.

[30] J. S. Boyer, "Plant productivity and environment," Science, vol. 218, no. 4571, pp. 443-448, 1982.

[31] R. D. Jackson, "Remote sensing of biotic and abiotic plant stress," Annual Reviews in Phytopathology, vol. 24, pp. 265287, 1986. 


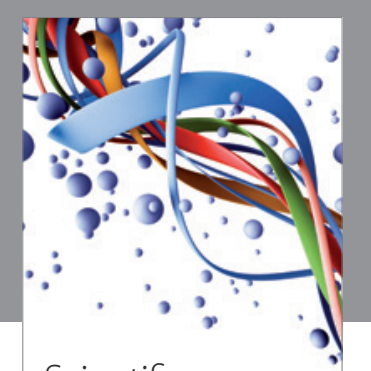

Scientifica
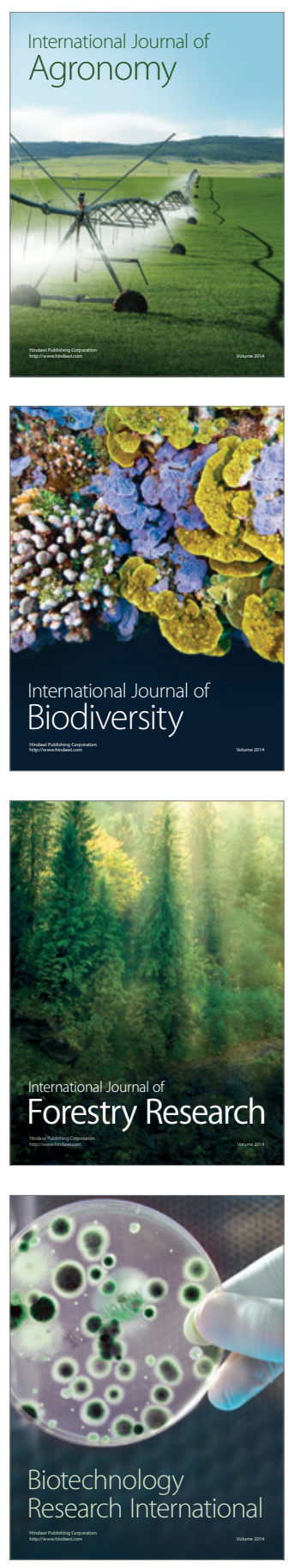
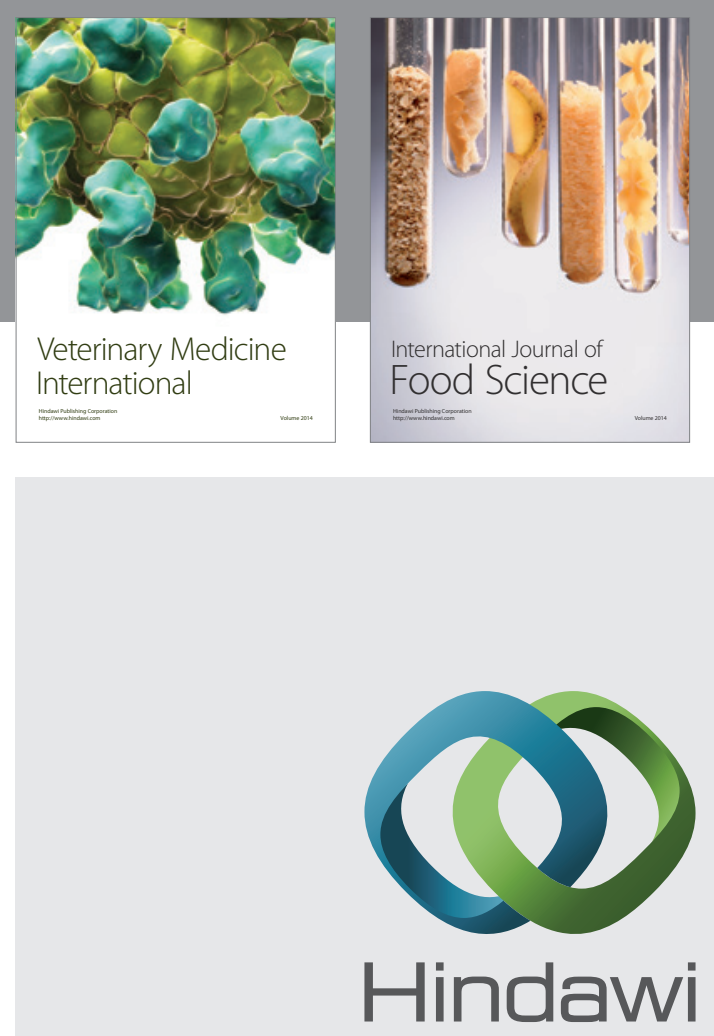

Submit your manuscripts at

http://www.hindawi.com
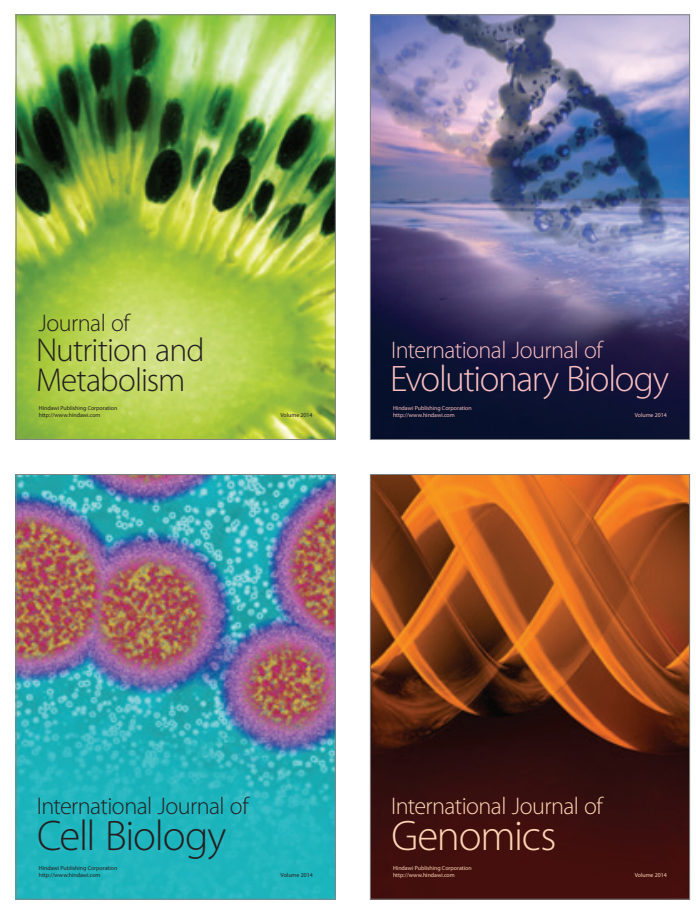
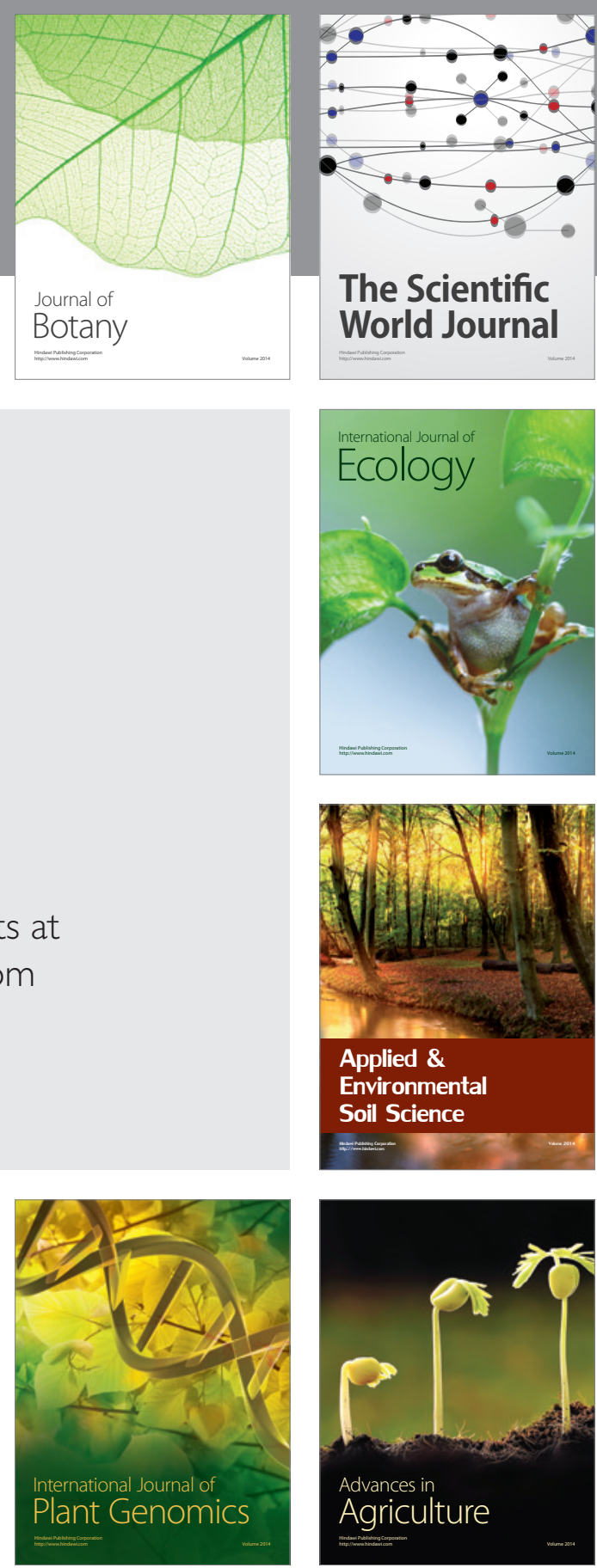

The Scientific World Journal
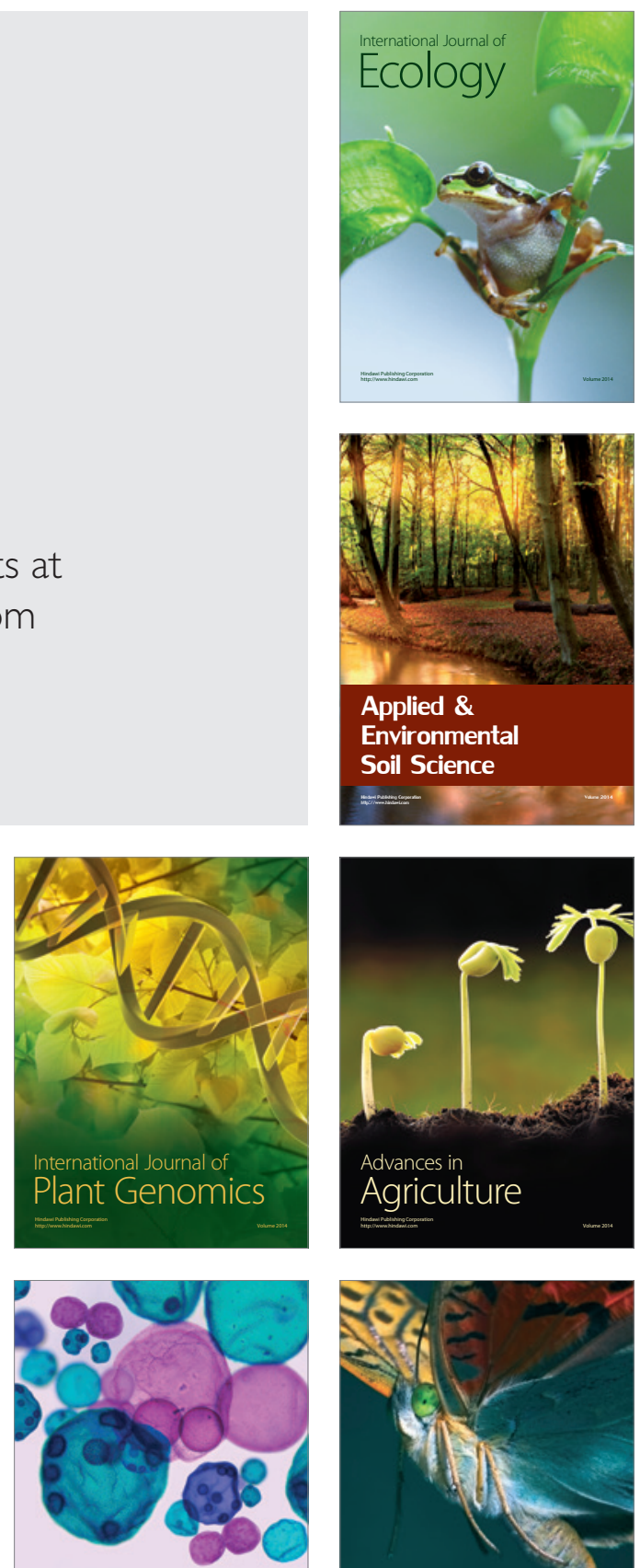

International Journal of Microbiology

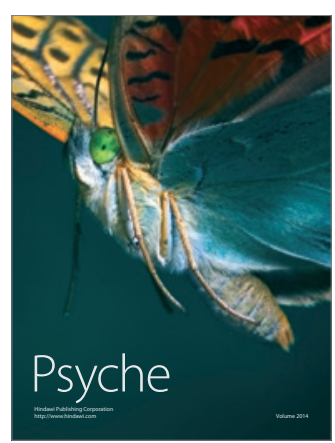

